\title{
PEMBINAAN TATA BAHASA DAN BENTUK SURAT-MENYURAT INDONESIA BERBASIS MICROSOFT DI DESA MANDALA, DUKUPUNTANG KABUPATEN CIREBON
}

\section{COLLOCULATES AND FORMS A MICROSOFT LETTER BASED IN THE VILLAGE OF MANDALA, DUKUPUNTANG, CIREBON}

\author{
${ }^{1)}$ Jimat Susilo, ${ }^{2)}$ Tri Pujiatna, ${ }^{3)}$ Siska Firmasari \\ ${ }^{1,2)}$ PBSI, FKIP Universitas Swadaya Gunung Jati Cirebon \\ ${ }^{3)}$ Pendidikan Matematika, FKIP Universitas Swadaya Gunung Jati Cirebon \\ Jalan Perjuangan No. 1 Cirebon
}

Email: jimat_cirebon@yahoo.com

\begin{abstract}
ABSTRAK
Tujuan pengabdian ini untuk meningkatkan kemampuan para perangkat desa dalam membuat surat dengan menerapkan teknologi komputer. Surat merupakan salah bentuk komunikasi tulis. Surat ditulis bertujuan untuk menyampaikan sesuatu kabar/berita/informasi secara tertulis. Penulisan dan pengorganisasian surat perlu mendapatkan perlakukan yang khusus agar maksud dan tujuan dapat disampaikan dengan baik Penulisan surat membutuhkan sebuah pemahaman tentang konsep bahasa dan format bentuk surat. Hal ini bertujuan agar maksud dan tujuan surat dapat diterima dengan baik oleh penerima surat. Penggunaan teknologi dalam penulisan surat akan berpengaruh pada kecepatan dalam penyampian informasi. Salah satu usaha yang dapat dimanfaatkan untuk memaksimalkan kegiatan pengelolaan surat-menyurat dengan memanfaatkan teknologi komputer. Teknologi komputer khususnya pemanfaatan perangkat lunak yang digunakan adalah metode langsung dengan menggunakan suatu pendekatan teknik pendampingan. Mitra dalam kegiatan ini adalah pemerintahan Desa Mandala Kecamatan Dukupuntang Kabupaten Cirebon. Hasil kegiatan ini berupa peningkatan kapasitas kemampuan para perangkat desa dalam proses penulisan surat dari segi penggunaan bahasa surat dinas yang baku sesuai dengan ejaan bahasa Indonesia serta bentuk surat dinas yang akan digunakan. Selanjutnya, pengguaan teknologi komputer bagi para perangkat Desa akan mempermudah dalam proses pembuatan surat masal secara singkat dan efisien dengan memaksimalkan fitur Mail Merge pada program Microsoft Word.
\end{abstract}

Kata kunci: Tata Bahasa Surat; Tata Bentuk Surat; Mail Merge

\begin{abstract}
The purpose of this service is to increase the ability of village officials to make letters by applying computer technology. Letters are a form of written communication. The written letter aims to convey something news/news/information in writing. Writing and organizing messages need to get special treatment so that the intentions and objectives can be appropriately carried. Writing letters requires an understanding of the concept of language and the format of the form of letters. It is intended for the purpose, and the recipient of the message can thoroughly receive the purpose of the message. The use of technology in writing letters will affect the speed in the delivery of information. One effort that can be utilized to maximize correspondence management activities is by using computer technology. Computer technology, especially the use of software used, is a direct method using a technical assistance approach. The partner in this activity is the government of Mandala Village, Dukupuntang District, Cirebon Regency. The results of this activity will be in the form of capacity building for village officials in the process of writing letters in terms of the use of official service language by Indonesian spelling and the structure of formal letters to be used. Furthermore, the use of computer technology for village officials will facilitate the process of making mass mailings in a short and efficient manner by maximizing the Mail Merge feature in the Microsoft Word program
\end{abstract}

Keywords: Letters Grammar; The form of the letter; Mail Merge

Submitted : 18 September 2019 Revision : 12 November 2019 Accepted : 20 Februari 2020 


\section{PENDAHULUAN}

Surat merupakan salah bentuk komunikasi tulis. Surat ditulis bertujuan untuk menyampaikan sesuatu kabar/berita/informasi secara tertulis. Oleh karena itu, sudah sepatutya penulisan dan pengorganisasian surat mendapatkan perlakukan yang khusus agar maksud dan tujuan dapat disampaikan dengan baik. Komunikasi dalam bentuk surat-menyurat tidak akan pernah ditinggalkan, baik pribadi maupun pemerintahan/organisasi. Penulisan surat pribadi dan resmi/pemerintah/organisasi selalu membutuhkan dua hal penting, yaitu bahasa dan bentuk surat.

Surat-menyurat yang biasa disebut korespondensi, merupakan alat penyampaian informasi atau kererangan-keterangan (keputusan, pernyataan, pemberitahuan, dan permintaan (Susanti, Sholikhah, Mareta, 2018). Oleh karena itu, proses penulisan surat membutuhkan sebuah pemahaman tentang konsep bahasa dan format bentuk surat. Hal ini diharapkan agar maksud dan tujuan surat dapat diterima dengan baik oleh penerima surat. Penggunaan bahasa surat khususnya surat resmi harus memperhatikan kaidah-kaidah bahasa Indonesia yang baik, benar, dan tepat serta efektif. Oleh karena itu, sudah menjadi suatu kewajiban bagi pengetik/pengonsep surat memahami kaidah-kaidah bahasa Indonesia dengan baik. Salah satu cara untuk memahami kaidah bahasa Indonesia, pengetik/pengonsep surat harus memahami tentang kaidah bahasa Indonesia buku Pedoman Umum Ejaan Bahasa Indonesia (PUEBI). Penggunaan bahasa yang baku dan tata cara penulisan yang baku akan mempermudah pemahaman pesan yang disampaikan serta akan mengurangi risiko salah tafsir (Purwandari, Setiawan, Saddhono, 2014).

Selain penggunaan bahasa Indonesia yang baik dan benar, pengetik/pengonsep surat baik pribadi maupun resmi harus mempunyai pengetahuan tentang tata bentuk surat bentuk surat Indonesia. Penggunaan bentuk surat merupakan salah satu bentuk ketaatan dalam penulisan surat Indonesia. Ada beberapa tata bentuk surat-menyurat Indonesia yang dapat digunakan, di antaranya: Indonesia lama, Indonesia baru, lurus penuh, setengah lurus, dan menggantung. Hal dapat dipelajari pada buku-buku tentang surat-menyurat resmi Indonesia.
Fungsi surat dalam kehidupan sehari-hari sangat penting untuk menyampaikan maksud dan tujuan dari sebuah informasi. Berikut fungsi surat yaitu 1) Surat sebagai alat atau sarana komunikasi tulis; 2) Surat sebagai alat bukti tertulis ; 3) Surat sebagai alat bukti historis; 4) Surat sebagai alat pengingat; 5) Surat sebagai dutaorganisasi; 6) Surat sebagai pedomankerja. (Soedjito \& Solchan, 2004).

Penggunaan teknologi dalam penulisan surat akan berpengaruh pada kecepatan dalam penyampian informasi. Menurut Priyadi \& Lestari (2018) kecepatan pengolahan data dan penyampaian informasi memiliki peran yang sangat penting bagi setiap intansi, data maupun informasi yang harus diolah tentu tidak memungkinkan dengan menggunakan cara manual. Artinya, bahwa pengelolan surat pada setiap instansi memerlukan sebuah sentuhan teknologi pengelolaan informasi guna kecepatan pengolahan data dan penyampaian maksud dan tujuan penulisan surat.

Salah satu usaha yang dapat dimanfaatkan untuk memaksimalkan kegiatan pengelolaan surat-menyurat dengan memanfaatkan teknologi komputer. Teknologi komputer khususnya pemanfaatan software yang mendukung kegiatan penyusunan surat menyurat adalah Microsoft Word. Menurut Fajri (2014), Microsoft Word merupakan salah satu software yang sering digunakan dalam dunia pendidikan dan perkantoran, untuk mengolah kata seperti membuat surat, makalah, laporan, dan sebagainya. Sehingga setiap pekerja di dunia pendidikan dan perkantoran dituntut untuk mampu menguasai keterampilan menggunakan perangkat lunak Microsoft Word. Menurut Ikhwani, Budiman, \& Rasyidan, 2015), Microsoft Word menjadi program pengolah kata yang handal dan paling banyak digunakanoleh pengguna komputer.

Mail merge adalah fitur yang berfungsi sebagai pengolah katadengan memasukkan nilai suatu variabel dari basis data ke dalam sebuah templat (Taljaard et al, 2015). Selanjutnyam Mail merge merupakan salah satu fasilitas yang yangdigunakan membuat dokumen dengan template yang sama (Fajar et $a l$, 2017). Artinya, bahwa fitur ini dapat digunakan sebagai secara terus-menerus tanpa harus membuat dokumen lanjatan hanya dengan memasukan variabel data. 
Berdasarkan latar belakang di atas, penulis akan melakukan kegiatan pembinaan penulisan Surat-menyurat Indonesia pada instansi pemerintahan. Pemilihan instansi pemerintahan didasari bahwa kegiatan suratmenyurat sering dilakukan, bahkan hampir setiap hari kegiatan surat-menyurat selalu ada surat keluar. Salah satu instansi pemerintahan penggunaa komunikasi tulis dalam bentuk surat-menyurat adalah Desa Mandala, Kecamatan Dukupuntang Kabupaten Cirebon.

Pemilihan lokasi Desa Mandala

Kecamatan Dukupuntang Cirebon didasari atas hasil observasi atau studi dokumen suratmenyurat di desa tersebut masih banyak kekurangan, di antaranya penggunaan kaidah kebahasaan belum sesuai kaidah bahasa Indonesia, bentuk surat yang belum memenuhi aspek estetika, dan struktur surat yang belum memenuhi kriteria surat resmi.Selain itu, tujuan pembinaan ini adalah untuk meningkatkan keterampilan menulis surat-menyurat Indonesia di Desa Mandala, Kecamatan Dukupuntang, Kabupaten Cirebon.

Salah satu usaha untuk meningkatkan kondisi tersebut dibuat suatu pembinaan tentang tata bahasa dan tata bentuk serta pengorganisasian dengan memanfaatkan teknologi komputer berbasis Microsoft. Kegiatan pembinaan yang dilakukan, mengarah pada kemampuan yang harus dikuasai pula oleh perangkat desa pada abad 21 yaitu penguasaan teknologi. Kegiatan perangkat desa terutama yang berkaitan dengan surat menyurat dan pemberkasannya jika masih menggunakan sistem konvensional maka tidak ramah lingkungan, dan akan berimbas pada mundurnya kinerja. Pemanfaatan teknologi komputer sebagai salah satu media dalam pembuatan surat bagi para perangkat desa akan berdampak pada peningkatan kemampuan SDM yang dimiliki sehingga menjadi lebih unggul.

\section{METODE}

Program pengabdian ini menggunakan metode langsung dengan pendekatan teknik pendampingan. Mitra kegiatan ini adalah pemerintahan Desa Mandala Kecamatan Dukupuntang Kabupaten Cirebon. Sasaran peserta kegiatan ini adalah para perangkat Desa Mandala Kecamatan Dukupuntang dan beberapa lembaga organisasi di bawah pemerintahan Desa Mandala. Kabupaten Cirebon yang berjumlah 34 peserta.

Para perangkat desa dan lembaga organisasi di bawah pemerintahan Desa Mandala merupakan pengguna dari kegiatan surat-menyurat. Pada kegaitan surat-menyurat yang dilakukan belum mangacu pada standar penulisan surat. Hal ini didasari pada pengetahuan dan keterampilan para peserta terhadap tata bahasa dan bentuk surat terbatas. Selain itu, latar belakang pendidikan para perangkat desa dan organisasi pemerintahan desa yaitu; SMP, SMA, dan Sarjana.

\section{HASIL DAN PEMBAHASAN}

Pendampingan yang dilakukan yaitu penggunaan tata bahasa dan tata bentuk surat. Ada beberapa hal yang harus dilakukan dalam pembinaan penulisan surat, antara lain (1) penggunaan tata bahasa dalam penulisan surat; (2) penggantian layout dan font dalam penyusunan surat; (3) pengaturan tampilan pada surat yang menarik; (4) menganalisis kesalahan surat yang telah dilakukan ( Hermawan, Utami \& Hadi, 2018). Di samping itu, dalam menulis surat resmi, penulis hendaknya dapat menyajikan pesan-pesannya dengan menggunakan bahasa yang logis, jelas, singkat, sistematis, dan mengacu pada format yang sesuai (Saddhono, Kundharu \& Slamet, 2014). Berdasarkan acuan tersebut, ditemukan beberapa kesalahan yang dilakukan dalam penulisan surat resmi oleh aparat Desa Mandala Dukupuntang Kabupaten Cirebon, yaitu 1) Penulisan nama kota. Sesuai dengan kaidah penulisan nama kota tidak perlu dicantumkan karena sudah nama kota sudah tercantum di dalam kepala surat. 2) Penggunaan ejaan di antaranya, pengunaan tanda baca apostrof (') pada kata "Jum'at" seharusnya "Jumat". Selain itu, pemborosan penggunaan bahasa pada bagian kepala surat tertulis Kantor Kuwu Desa Mandala seharusnya Kantor Desa Mandala. Alamat yang dituju. "Kepada Yth." seharusnya "Kepada" atau "Yth.", pilih salah satunya. Jika hal yang dituju berupa nama perorangan maka mengunakan kata "Yth.". Jika hal yang dituju berupa pejabat pemerintah/swasta maka mengunakan kata "Kepada". Setelah dilakukan pembinaan tentang tata bahasa dan tata benuk surat ini, 
para peserta sudah mampu menerapkan penulisan surat-menyurat sesuai dengan kaidah yang berlaku, baik dari segi bentuk maupun bahasa surat.

Selanjutnya, penerapan teknologi komputer dalam kegiatan ini, peserta dikondisikan pada situasi pembuatan surat udangan secara masal kepada beberapa penerima surat dan alamat yang berbeda-beda dengan hanya menulis satu surat udangan sebagai master dan membuat input data berupa nama penerima dan alamat yang berbeda-beda pada program Microsoft (Ms) Excel.

Menurut Yuliana (2007), microsoft adalah salah satu aplikasi Microsoft Office yang diciptakan untuk memberikan kemudahan dalam membuat dan menangani pengolahan suatu data base. Salah satu bentuk aplikasi mikrosof yang digunakan dalam pendampingan penulisan surat ini yaitu fitur Mail Merge. $P$ eserta didampingi dalam mengoprasikan fitur tersebut dengan baik sesuai dengan mengikuti langkah-langkah penggunaan fitur Mail Merge. Kemampuan para perangkat desa dalam menggunakan fitur ini termasuk dalam kategori baik. Hal ini dapat dilihat dari hasil observasi yang dilakukan .

1. Proses pembuatan Master Surat Undangan : Pada proses ini para peserta melaksanakan proses pembuatan pada software Microsoft Office Word Selanjutnya, menyimpan file tersebut dan diberi nama Master Surat Undangan pada drive D. Pada bagian ini para peserta membuat sebuah folder agar memudahkan dalam mencari data surat undangan yang dibuat pada sebuah drive di komputer. Pada kegiatan ini peserta mendapatkan predikat sangat baik.

2. Proses pembuatan Data Based Surat Undagan: Pada kegiatan ini, para peserta melaksanakan pembuatan Data Based Surat Undangan dengan menggunakan software Microsoft Office Excel kedalam bentuk tabel penerima dan alamat penerima. Selanjutnya, peserta menyimpan pada drive $D$ dengan nama file Data Based Surat Undangan pada folder yang sama saat menyimpan data Master Surat Undangan. Pada kegiatan ini peserta medapatkan predikat sangat baik.
3. Proses memasukkan Data Based Surat Undangan pada Master Surat Udangan : Setelah kedua file tersebut dibuat, Selanjutnya peserta memasukan Data Based Surat Undangan dengan membuka dokumen file Master Surat Undangan pada Microsoft Office Word kemudian meng-klik Mailing > Select Recipients >>Use an Existing List >>OK. Selanjutnya, peserta menempatkan kursor pada bagian yang akan diisikan nama penerima surat kemuidan klik Mailing>>Insert Merge Field>>nama penerima surat. Dan, untuk alamat penerima surat dilakukan secara serupa dengan langkah memasukan data nama penerima surat. Pada bagian ini, peserta mendapatkan predikat baik.

Kegiatan pengabdian kepada masyarakat tentang penggunaan tata bahasa dan bentuk surat dinas, serta penggunaan teknologi komputer berupa pemanfaatan fitur Mailings >> Mail Merge bagi para perangkat desa ini menghasilkan sebuah buku pedoman penulisan surat dinas berbasis Microsoft. Melalui buku pedoman ini, para perangkat desa, khususnya Desa Mandala Kecamatan Dukupuntang Kabupaten Cirebon dan desa lain di seluruh Indonesia pada umumnya diharapkan dapat menerapkan kaidah dalam proses penulisan surat, baik dari segi tata bahasa dan tata bentuk. Selanjutnya, penerapan teknologi komputer dengan memaksimalkan fungsi fitur Mailings $>>$ Mail Merge dalam buku ini dapat membantu para perangkat desa dalam pembuatan surat masal secara efektif dengan mengikuti beberapa langkah-langkah yang mudah dipahami.

\section{SIMPULAN}

Berdasarkan hasil pembahasan kegiatan bahwa program ini berjalan dengan baik dengan total peserta yang mengikuti kegiatan ini sebanyak 34 peserta. Penggunaan tata bentuk dan bahasa surat yang dilakukan sudah mengikuti kaidah penulisan bahasa surat dan standar bentuk surat. Selanjutnya, penggunaan fitur Mail Merge dalam pembuatan surat masal para perangkat desa dapat menggunakan fungsi fitur tersebut dengan mudah di bawah bimbingan tutor. 


\section{DAFTAR PUSTAKA}

Fajar, Y., Rohaeni, O., Permanasari, Y., Iswani, A, Mulkiya, K., (2017). Meningkatkan Kompetensi Guru SMA dan Sederajat Melalui Pelatihan Pembelajaran Berbasis TIK. Ethos: Jurnal Penelitian dan Pengabdian, 5 (2), 175-181

Fajri, R., (2014). Multimedia Pembelajaran Microsoft Word 2007 Menggunakan Macromedia Flash 8.0. Jurnal Lentera, 14 (2), 41-48

Hermawan, A., Utami, S., Hadi, S., (2018). Pelatihan Korespondensi untuk Meningkatkan Keterampilan Menulis Surat pada Pengurus Karang Taruna Desa Candirejo Kecamatan Ponggok Kabupaten Blitar. J-ABDIPAMAS (Jurnal Pengabdian Kepada Masyarakat) , 2 (1), 111-115.

Ikhwani, Y., Budiman, H., \& Rasyidan, M. (2015). Pelatihan Aplikasi Microsoft Word 2013 pada SMP H. A. Johansyah. A Banjarmasin. Jurnal Al-Ikhlas, 1(1).11-14

Purwandari, H.S., Setiawan, B., Saddhono, K., (2014). Analisis Kesalahan Berbahasa Indonesia pada Surat Dinas Kantor Kepala Desa Jladri. Basastra, Jurnal Penelitian Bahasa, Sastra Indonesia dan Pengajarannya, 1(3).478-489
Priyadi, D.A. \& Lestari, E.W., (2018). Perancangan Sistem Informasi Surat Menyurat Pada Kantor Desa Tanjungsari Kutowinangun Kebumen Berbasis Desktop. Jurnal Teknik Komputer, 4(2), 84-91

Saddhono, Kundharu \& Slamet., (2014). Pembelajaran Keterampilan Berbahasa Indonesia: Teori dan Aplikasi Edisi 2. Yogyakarta: Graha Ilmu.

Soedjito \& Solchan T.W. (2004). Surat Menyurat Resmi Bahasa Indonesia. Bandung: Remaja Rosda Karya

Susanti, T., Sholikhah, F., Mareta, M., (2018). Pengembangan Model Aplikasi e-Surat Sebagai Peningkatan Kompetensi Bidang Manajemen Rekod. Jurnal Gama Societa, 1 (1), 20-30

Taljaard, M., Weijer, C., Chaudhry, S.H., \& Grimshaw, J. (2015). Mail Merge Can be Used to Create Personalized Questionnaires in Complex Survey. BMC Research Notes, 8 (574), 2-6. doi: 10.1186/s13104-015-1570-5

Yuliana, Oviliani Yenty (2007). Pembuatan Aplikasi Database Microsoft Access. Yogyakarta: Graha Ilmu 